\title{
ESTRATÉGIAS DE CONTROLE VISANDO A FLUTUAÇÃO DE Enneothrips flavens (Moulton, 1941) (Thysanoptera: Thripidae) EM SEMI-CAMPO
}

Tamiris Marion de Souza ${ }^{1}$, Fabrício Oliveira Fernandes ${ }^{1}$, Marcos Doniseti Michelotto ${ }^{2}$, Ignácio José Godoy $^{3}$ e Antonio Carlos Busoli ${ }^{4}$

\footnotetext{
${ }^{1}$ Pós-graduandos em Agronomia (Entomologia Agrícola), FCAV/UNESP, Jaboticabal, SP, tamirismdsouza@hotmail.com (Apresentadora do trabalho), fabriciof9@gmail.com; ${ }^{2} \mathrm{PqC}$., Bolsista Produtividade CNPq, Apta, Polo Centro Norte, Pindorama, SP, Email: michelotto@apta.sp.gov.br; ${ }^{3}$ Pesquisador Científico do IAC, Campinas, SP, Email: ignaciojgodoy@yahoo.com.br, ${ }^{4}$ Docente da FCAV/UNESP, Jaboticabal, SP, antonio.c.busoli@unesp.br.
}

RESUMO: O presente trabalho teve como objetivo avaliar a resposta no controle do tripes-doprateamento (Enneothrips flavens (Moulton, 1941) (Thysanoptera: Thripidae)) nos solos argissolo vermelho - amarelo e neossolo quartzarênico. O experimento foi conduzido em delineamento inteiramente casualizado com 10 repetições sendo cada vaso $(15 \mathrm{~L})$ considerado uma repetição. A semeadura foi realizada com a cultivar IAC OL3, em esquema fatorial $4 \times 2$, tendo como tratamentos as estratégias de controle: silício via foliar, silício via solo, inseticida, testemunha. Os resultados indicaram que o Argissolo Vermelho-Amarelo não obteve interação com os tratamentos submetidos, ocasionando maiores flutuações de Enneothrips flavens. Contudo, a aplicação de silício via solo, contribuiu no controle do tripes-do-prateamento independentemente do tipo do solo.

Palavras-Chave: Arachis hypogaea L., silício na agricultura, tripes-do-prateamento.

\section{INTRODUÇÃO}

Devido as condições climáticas ocorridas na safra 2018/2019, o cultivo do amendoim (Arachis hypogaea) no Brasil apresentou redução na produtividade de aproximadamente $21,2 \%$, em relação à safra 2017/2018. O Estado de São Paulo, considerado o maior produtor brasileiro obteve um aumento na área cultivada de 5,3\%, devido aos altos valores. No entanto, a incidência de artrópodes-praga contribui na redução significativa da produtividade da cultura (ALHOUSARI \& GREGER, 2018; CONAB, 2019).

A cultura do amendoim é ameaçada por diversos artrópodes-praga, sendo Enneothrips flavens (Moulton, 1941) (Thysanoptera: Thripidae) conhecida como tripes-do-prateamento o principal inseto. O manejo inadequado do inseto pode proporcionar perdas em torno de $70 \%$ na produtividade 


\section{Encontro Sobre a Cultura do Amendoim \\ 15 a 17 de agosto de 2019 na Estação de Eventos Cora Coralina e FCAV/UNESP, Jaboticabal-SP}

(GABRIEL, 2016; MICHELOTTO et al., 2017). Contudo, o uso de silicatos e o tipo de solo, no cultivo do amendoim pode contribuir no controle do inseto-praga (TUBAÑA \& HECKMAN, 2015).

Diante do exporto, o presente trabalho teve como objetivo avaliar a resposta no controle do tripes-do-prateamento (Enneothrips flavens (Moulton, 1941) (Thysanoptera: Thripidae)) nos solos argissolo vermelho - amarelo e neossolo quartzarênico.

\section{MATERIAL E MÉTODOS}

O experimento foi instalado no Departamento de Fitossanidade da FCAV/Unesp, SP, Brasil. O delineamento utilizado foi em blocos inteiramente casualizado (DIC) em esquema fatorial $4 \times 2$. Cada vaso de $15 \mathrm{~L}$ foi considerado uma repetição, totalizando 10 repetições por tratamento. A semeadura foi realizada com a cultivar IAC OL3 e os tratamentos foram: aplicação de silício via foliar; aplicação de silício via solo; aplicação de inseticida convencional e testemunha (ausência de aplicação) nos solos argissolo vermelho - amarelo e neossolo quartzarênico (Areia Quartzosa).

A aplicação do silício via solo foi realizado através da utilização do silicato de cálcio (Agronelli $^{\circledR}$ ) na dosagem de $2.608 \mathrm{Kg} \mathrm{ha}^{-1}$, contendo $23 \%$ de $\mathrm{SiO}_{2} ; 41 \% \mathrm{CaO} ; 11 \% \mathrm{MgO}$. O isolamento do efeito do silício nos outros tratamentos, foi realizado a partir da aplicação de $2.608 \mathrm{~kg}$ $\mathrm{ha}^{-1}$ de calcário.

As pulverizações dos inseticidas e da aplicação de silício via foliar foram realizadas com auxílio de um pulverizador manual com capacidade de $2 \mathrm{~L}$, calibrado para aplicar um volume de $352 \mathrm{~L}$ $\mathrm{ha}^{-1}$ de calda. As aplicações foram realizadas a cada 15 dias, de acordo, com os seus respectivos tratamentos.

As avaliações foram realizadas semanalmente, iniciando-se aos 15 dias após a emergência (DAE), por meio da amostragem ao acaso de 5 folíolos jovens (ainda fechados), por vaso sem a retirada dos mesmos da planta, verificando a presença de tripes. Os dados obtidos foram submetidos à análise de variação e as médias comparadas pelo teste de Tukey a 5\% de probabilidade.

\section{RESULTADOS E DISCUSSÃO}

No tratamento testemunha observou-se um aumento gradativo na flutuação populacional da praga em ambos os solos, porém aos $56 \mathrm{DAE}$ verificou-se um pico, apresentando uma média de $10 \mathrm{E}$. flavens/50 folíolos no solo neossolo quartzarênico. Entretanto, o solo argilosso vermelho-amarelo teve um comportamento distinto com média de 6 E. flavens/50 folíolos. Após 83 DAE, os resultados indicam que o argissolo vermelho-amarelo apresentou cerca de 8 E. flavens/ 50 folíolos e o neossolo quartzarênico com cerca de 3 E. flavens/ 50 folíolos (Figura 1 a).

No tratamento utilizando silício via foliar, verificou-se maior flutuação no solo argissolo vermelho-amarelo, atingindo o maior pico aos 56 DAE. De acordo com Camargo (2016) a flutuação 


\section{Encontro Sobre a Cultura do Amendoim \\ 15 a 17 de agosto de 2019 na Estação de Eventos Cora Coralina e FCAV/UNESP, Jaboticabal-SP}

populacional do inseto-praga é atribuído ao solo por apresentar baixos teores de argila, e proporções suficientes de silício. Enquanto, no solo neossolo quartzarênico a flutuação atingiu patamares em torno de 4 E. flavens/50 folíolos (Figura 1 b). Os resultados foram observados por Dalastra et al. (2011), ao utilizar aplicação foliar de Si na cultura do amendoim cultivado em solo latossolo vermelho distrófico.

Os tratamentos com silício via solo (Figura 1 c) e inseticida (Figura 1 d), apresentou-se flutuações populacionais semelhantes, sendo que no tratamento com silício via solo (Figura $1 \mathrm{c}$ ) houve um pico aos 56 DAE. Essa diminuição na flutuação é atribuída pela absorção de silício na planta, devido ao silício ser incorporado na parede celular (KÖRNDORFER et al., 2003, MITANI \& MA, 2005). Porém, no tratamento com inseticida (Figura $1 \mathrm{~d}$ ), a flutuação foi menor, com cerca $3 E$. flavens/50 folíolos (Figura $1 \mathrm{~d}$ ).
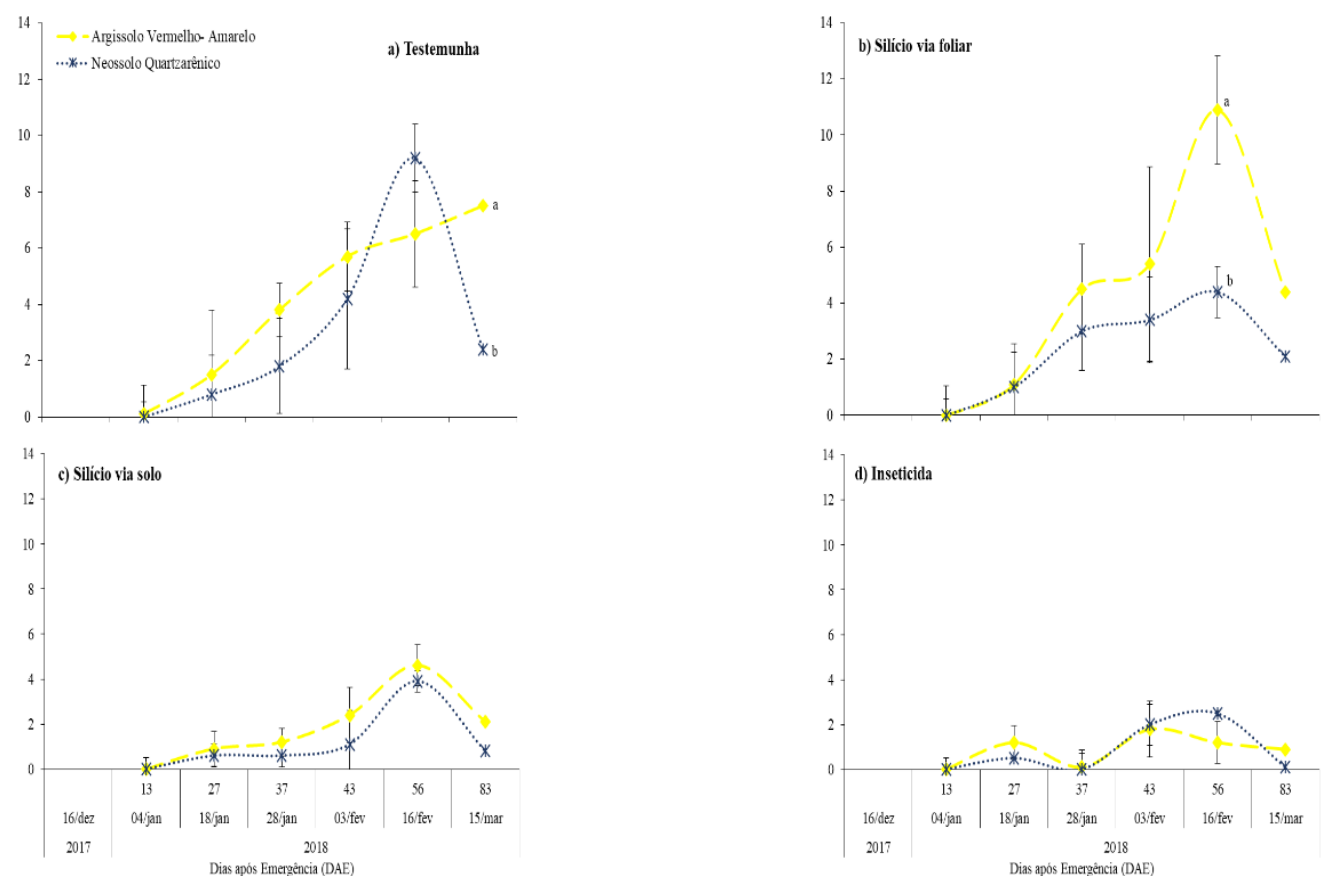

Figura 1. Flutuação de Enneothrips flavens em função das estratégias de controle na cultivar IAC OL3 em independente do solo, 2017/2018 Jaboticabal, SP. Pontos seguidos de mesma letra em cada data de avaliação não diferem entre si pelo teste de Tukey a $5 \%$ de probabilidade de erro.

$\mathrm{Na}$ figura 2, observou-se que no argissolo vermelho-amarelo a flutuação populacional apresentou índices maiores, aos 37, 43, 56 e 83 DAE. Nas avaliações, observou-se comportamentos semelhantes nos tratamentos submetidos, onde o tratamento com silício via foliar e a testemunha, diferenciou-se dos tratamentos com silício via solo e com inseticida (Figura 2 a). Aos 56 DAE, verificou-se um pico de flutuação, apresentando cerca de 11 E. flavens $/ 50$ folíolos no tratamento com silício via foliar, cerca de 7 E. flavens $/ 50$ folíolos no tratamento testemunha, 4 E. flavens $/ 50$ folíolos no tratamento com silício via solo e 14 E. flavens/50 folíolos no tratamento com inseticida. 


\section{Encontro Sobre a Cultura do Amendoim \\ 15 a 17 de agosto de 2019 na Estação de Eventos Cora Coralina e FCAV/UNESP, Jaboticabal-SP}

No neossolo quartzarênico, a flutuação populacional apresentou baixa incidência. Porém o mesmo comportamento do solo anterior, com os tratamentos silício via foliar e testemunha apresentando as maiores flutuações, em relação aos tratamentos silício via solo e com inseticida (Figura 2 b). Também apresentou um pico aos 56 DAE, observando o tratamento testemunha com a maior flutuação, com cerca de 10 E. flavens $/ 50$ folíolos, o no tratamento com silício via foliar com 4 E. flavens $/ 50$ folíolos, no tratamento com silício via solo com cerca de 4 E. flavens $/ 50$ folíolos e no tratamento com inseticida com 3E. flavens/50 folíolos (Figura $2 \mathrm{~b}$ ).

Korndorfer \& Gascho (1999) afirmam que independentemente da fonte de silicato utilizado, houve um aumento no $\mathrm{pH}$ do solo em relação a testemunha, como também apresentaram insuficiência de Fe.

Este fato, por si só, explica os resultados observados neste experimento, na qual as plantas de amendoim cultivadas no solo argissolo vermelho-amarelo apresentaram-se maiores flutuações de tripes do que as plantas cultivadas no solo neossolo quartzarênico.
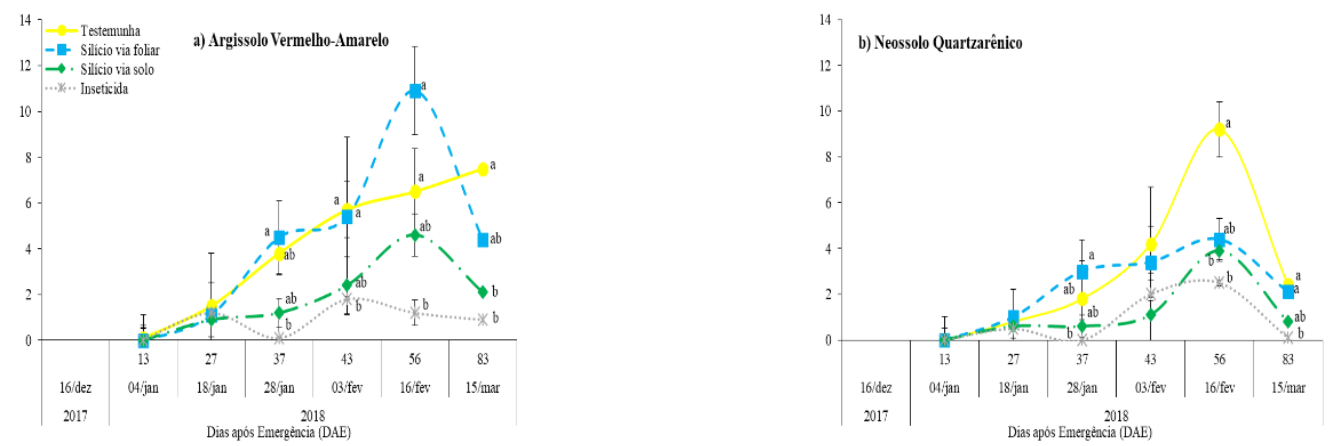

Figura 2. Flutuação de Enneothrips flavens independente ao solo e em função das estratégias de controle, 2017/2018, Jaboticabal, SP. Pontos seguidos de mesma letra em cada data de avaliação não diferem entre si pelo teste de Tukey a 5\% de probabilidade de erro.

\section{CONCLUSÕES}

O argissolo vermelho-amarelo não interage com os tratamentos recebidos, ocasionando maiores flutuações de Enneothrips flavens;

O neossolo quartzarênico interage com o silício via solo e influência na baixa flutuação de Enneothrips flavens;

A aplicação de silício via solo, obteve resultados satisfatórios no auxílio ao controle de $E$. flavens independentemente do solo; 


\section{Encontro Sobre a Cultura do Amendoim}

15 a 17 de agosto de 2019 na Estação de Eventos Cora Coralina e FCAV/UNESP, Jaboticabal-SP

\section{AGRADECIMENTOS}

Ao Conselho Nacional de Desenvolvimento Científico e Tecnológico (CNPq), processo $132353 / 2017-2$.

\section{REFERÊNCIAS BIBLIOGRÁFICAS}

ALHOUSARI, F.; GREGER, M. Silicon and Mechanisms of Plant Resistance to Insect Pests. Plants, v. 7, n. 2, p. 33, 2018.

CAMARGO, M.S. 2016. Efeito do silício na tolerância das plantas aos estresses bióticos e abióticos.

Revista International Plant Nutrition Institute, IPNI, n.155, p. 1-8, 2016.

CONAB. Companhia Nacional de Abastecimento. Disponível em: < https://www.conab.gov.br/infoagro/safras/graos/boletim-da-safra-de-graos/item/dow> Acesso em: 04 jun 2019.

DALASTRA, C.; CAMPOS, A. R.; FERNANDES, F. M.; MARTINS, G. L. M.; CAMPOS, Z. R. Silício como indutor de resistência no controle do tripes do prateamento Enneothrips flavens Moulton, 1941 (Thysanoptera: Thripidae) e seus reflexos na produtividade do amendoinzeiro. Ciência e Agrotecnologia, v. 35, n. 3, p. 531-538, 2011.

GABRIEL, D. Pragas do amendoim. Gramado, Campinas: Instituto Biológico - APTA, 2016, 25p. (Instituto Biológico - APTA. Documento técnico, 26).

KÖRNDORFER, G. H.; GASCHO, G. J. Avaliação de fontes de silício para arroz. In: I congresso Nacional de Arroz Irrigado, Anais... Pelotas, p. 313-316, 1999.

KÖRNDORFER, G. H.; PEREIRA, H. S.; CAMARGO, M. S. Silicatos de cálcio e magnésio na agricultura. Uberlândia: Grupo de pesquisa "Silício na agricultura": UFU, 2003, 22p. (Boletim técnico 1).

MICHELOTTO, M. D.; GODOY, I. J.; PIROTTA, M. Z.; SANTOS, J. F.; FINOTO, E. L.; FÁVERO, A. P. Resistance to thrips (Enneothrips flavens) in wild and amphidiploid Arachis species. PLoS ONE, v. 12, n. 5, p. e0176811, 2017.

MITANI, N.; MA, J. F. Uptake system of silicon in different plant species. Journal of Experimental Botany, v. 56, n. 1, p. 1255-1261, 2005.

TUBAÑA, B. S.; HECKMAN, J. R. Silicon in Soils and Plants. In: Rodrigues F., Datnoff L. (eds) Silicon and Plant Diseases. Springer, Cham, v. 12, n.1, p. 7-51, 2015. 